\title{
Dirt and the Penetration of Social Fabrics: Rising from the Common to the Uncommon
}

\author{
Dr. Chris Echeta \\ Department of Visual and Creative Arts, \\ Federal University, Lafia-Nasarawa State, Nigeria \\ E-mail: echetachris@yahoo.com \\ Elizabeth Esege \\ Department of Visual Arts and Technology, \\ Cross-River University of Technology, Calabar-Nigeria \\ E-mail: lizdon2002@yahoo.com
}

\section{Doi:10.5901/mjss.2014.v5n2p423}

\section{Abstract}

The wheels that carry national economies are hooked to the engine of research. The word "research" carries with it the intrinsic mentality of exclusive laboratory environment. In this case, it is not so. This context includes the use of far-flung production traditions whose investigative stages have been lost in antiquity. Pottery is one of such areas. Among the lgbos of southeastern Nigeria, one of the derogatory names of clay is 'apiti' implying "Dirt". Many, even outside this geographical catchment, feel this is what clay is, yet it has penetrated the social fabrics of every generation and mobilized its potentials to add up to the society's path to stability. Art has offered itself to this "dirt" or is it the other way round, for the making of pottery for function and aesthetics and, by extension, facilitated the employment of thousands in time. The much-talked-about selfemployment, poverty alleviation, and wealth-generation are hooked to the fact that cultures have free-willing methods of training its population. Informal education and training have collaborated to facilitate this where the apprenticeship system has played the mainline role in raising traditional entrepreneurs. Beyond this, historical and documentations dimensions provided by clay cannot be dismissed by the wave of the hand. This paper aspires to explore the social mobility of this common clay and excavate other areas of latent but indispensible involvements in Art, Culture, Documentation and Tourism.

Keywords: Dirt, Social mobility, skill-acquisition, wealth-generation, tourism, apprenticeship.

\section{Introduction}

Many have suggestively provided clues that the environment and social events can only be meaningful in the light of "contemporariness" or modernity. This attitude has been seen in literary works and even policies of governments. Such viewpoints have written off or grossly underestimated the social interventions of home-grown structures, materials and ideas. The consuming "oversea"/ "foreign" brainwashing has also undermined local creativity improvisation. The Nigerian government, in the 80's, put together and pursued a policy it called Technological Transfer. The people in government at the time believed the West and the East will, in line with their verbal empty assurances, transfer their technologies to the so-called developing nations of which Nigeria is classified as one. The futility and the emptiness of this national policy was glaring a few short years upfront as it, contrary to expectations, endorsed the total emasculation and abandonment of local technological initiatives and structures and slowed down the zeal for experimentation with local raw materials. It failed woefully because it proved itself a wrong and unrealistic policy. It must have thought the local ideas were dirt.

Before now, traditional medical efforts have been roundly discarded by the "educated". While not endorsing a blanket and acceptance of all traditional medicines, the writers of this paper believe that the new national attitude of researching into them is a welcome development. Art and its practice have also been treated in many ways as described above. Many of the greatest African art objects in ivory, wood, clay and other materials as at today are resident beyond the Nigerian borders. Even though some were punitively snatched away due to superior military powers, others were first negotiated and sold or smuggled out with the connivance of Nigerians. All the efforts to bring them 'back to base', including the original of FESTAC 77 mask has failed. This underscores the quality of craftsmanship invested in them by their Nigerian makers. It sustained refusal of the nations now housing these works presents the mirror opposite of their quality-a big loss in deed. 
The uses of dirt are very many.

Clay tablets were used as the first known writing medium, inscribed with cuneiform script through the use of a blunt reed called a stylus. Clays sintered in fire were the first form of ceramic. Bricks, cooking pots, art objects, dishware, and even musical instruments such as the ocarina can all be shaped from clay before being fired. Clay is also used in many industrial processes, such as paper making, cement production, and chemical filtering. Clay is also often used in the manufacture of pipes for smoking tobacco. Until the late 20th century bentonite clay was widely used as a mold binder in the manufacture of sand castings. Clay, being relatively impermeable to water, is also used where natural seals are needed, such as in the cores of dams, or as a barrier in landfills against toxic seepage (lining the landfill, preferably in combination with geotextiles). ${ }^{\left[{ }^{[}\right]}$Recent[when?] studies have investigated clay's absorption capacities in various applications, such as the removal of heavy metals from waste water and air purification Medical and agricultural usesA traditional use of clay as medicine goes back to prehistoric times. An example is Armenian bole, which is used to soothe an upset stomach, similar to the way parrots (and later, humans) in South America originally used it. ${ }^{[4]}$ Kaolin clay and attapulgite have been used as anti-diarrheal medicines. Clay as a building materialClay is one of the oldest building materials on Earth, among other ancient, naturally-occurring geologic materials such as stone and organic materials like wood. Between one-half and two-thirds of the world's population, in traditional societies as well as developed countries, still live or work in a building made with clay as an essential part of its load-bearing structure. Also a primary ingredient in many natural building techniques, clay is used to create adobe, cob, cordwood, and rammed earth structures( en.wikipedia.org/wiki/Clay)

Much as the above uses are copious, these scientific discoveries are late-comer discoveries to what this paper set out to do. The paper has invested its energy in the raw locally-sourced clay which, more or less terminates at the terracotta stage of firing and locall decorations. This is the reach of the traditional potters who have, perhaps, used this dirt for hundreds of thousands of years.

"Dirt", (local clay), is a bundled concentrate of potentials whose social mobility is worthy of mention. It has kept and still keeping the records of traditional, contemporary and modern issues, including art, culture and tourism. Job creation, wealth-generation and health matters are also a part of what clay can and has addressed. The pathway to the above are dealt with in this paper.

\section{Knowledge and Application}

Clay intervenes in human and environmental issues causing them to unite for the benefit of the society. The knowledge of clay as a raw material and its use date back to antiquity whose time origin cannot be pinpointed. This word "knowledge" does not reside in the identification of the material only. It spreads out to include its formation, characteristics and other components of its behavior in room temperature as well as at elevated heat levels. These behaviours can be classified under two umbrellas-physical and chemical properties. The traditional potter who is the generator of pottery forms for art and functions is usually at home with the above characteristics. She is not likely to characterize them as physical and chemical properties, but a mere hand contact with clay gives out these qualities, even the maturing temperature of local clays. The application of the above knowledge finds its expression in the production of clay works of art and works of clay for function. According to Okafo (2005):

The traditional pottery is highly cherished among Nigerians, not only for its utilitarian values, but also for its contributions to enriching the traditional and cultural activities of the people. For example, among the lgbos of southeastern Nigeria, traditional pottery plays very prominent roles in the social life of the people eg. Traditional marriage, title-taking, traditional worship and burial ceremonies, pots are essential features in these activities.(Okafo,2005).

The master-potter, in the course of the apprenticeship training, establishes a close and friendly relationship with all the apprentices. This lays the foundation for trust which prepares beneficiaries for a fulfilled life. This flow of trust engages all the members of the group in a strong bond of friendship which lasts long after their training. The social benefits of such encounters cannot be over-emphasized.

The communication dimension of pottery is also a part of the social and historical benefits of the art embedded in pottery. Ekong in Okunna (2009) declares "pottery as a primal source of historical record, not only from pot shards found in archaeological sites but the continued practice of the craft and its marriage to traditional beliefs.

Okunna (2009) goes ahead to note that there is a strong link between pottery and Igbo cosmology. He says that aesthetic elements are drawn from "vegetal environment" largely from plant and animal life. The curvilinear surface embellishments of Uli idiom in concentricity which manifests in the Igbo-Ukwu pottery excavated in the $9^{\text {th }} / 10^{\text {th }}$ century by 
Thurstan Shaw gives credence to the above fact. The circles and concentricity represent generational continuity and long life. These elements can also be seen on the hemispherical pot locally reffered to as 'Oku'

Fig. 1. Oku..The hemispherical vessel from Inyi with all-over Uli decorations

\section{Copyright: Chris Echeta}

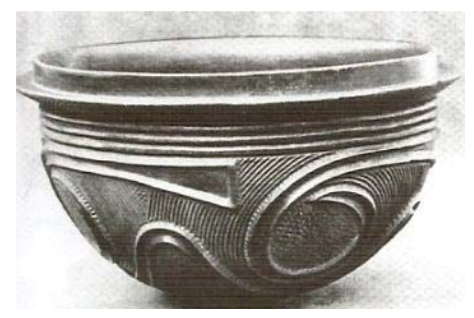

Not only does pottery (the use of dirt) minister to the function needs of its host community, it also addresses the beauty need of its users.

\section{Apprenticeship and Social Education}

The art of pottery is mostly kick-started in the apprenticeship system. This apprenticeship is the teaching and learning of the pottery trade from the first principles of raw material appreciation, to the "doing" of the forms, down to the last stage which involves the firing of the products. The learning team usually involves a loose sorority of local females, usually much younger than the master-potter that does the teaching.

Successful apprenticeship relies, not on formal lesson notes as in formal education, but on the trifurcated platform of looking, hearing and doing. The young girls sit or stand around the master-potter intently attentive, focusing on the issues raised in the process of teaching. Apart from educating them on the art of pottery, the system prepares them to be diligent in thinking and committed in attitude. There is usually a carry-over of these pleasant attributes into other areas of life, including the home. The benefits of hard work which pottery can symbolize are imbued/imparted into these young girls which they multiply as they get into their matrimonial homes. Their children, in time, will sift and imbibe these attitudes in their mothers' family life. Dealing with the art drags along with it, other baggage which also are beneficial to the apprentices. Being that the apprentices are women, (birds of the same feather), they are able to receive teachings on issues that are not pottery. Their informal discussions even when they are learning touch on many off-centre topics because they are not the main purpose for which the learners have come. Such off-centre topics touch on any issue peculiar to their gender. The master-potter reminds them of the "girlness" in them and some social expectations on them, sexuality and its development. Other areas include marriage and family life, childbirth and child-upbringing. In this way, the art has intervened into the culture of the society through character-moulding and diligence-motivated attitudes.

\section{Skill-Acquisition, Employment and Wealth-Generation}

The Nok Culture is a 'dirt'-based culture which analyses and interprets the social and artistic temperament of the age. To impart skills is the ultimate objective of the apprenticeship system. Graduates from the system engage themselves in gainful employment from which point they grow and become employers of labour. By acquiring a skill, they have been positioned to engage themselves gainfully and from that vantage point, walk down the path of wealth-generation. The ultimate landing pad for skill acquisition is wealth-generation wherein lies the motivation. Not only do they enjoy better life individually, such well-being collectively adds up to the socio-national economy.

When the youth are gainfully employed, the trigger on social restiveness is permanently broken. They will be in short supply of extra time for riots and many other anti-social activities. Prostitution is likely to be on the decrease and the prospects of enlisting new membership will obviously not be guaranteed. This scenario wears away the attractiveness of loose life therefore discouraging HIVIAIDS contagion. This will ultimately raise the social health status of the society and by extension, the nation. Even those who are already facing the wrong directions can be recalled and redirected with jobs and the prospects of earning a living. 


\section{Historical Documentation and Archaeology}

When clay is fired to and beyond $500^{\circ} \mathrm{C}$ it loses its chemically-combined water and becomes indissoluble. In that state, it can remain buried for hundreds and thousands of years without any form of depreciation. The fired biscuit or terracotta, because of its indissolubility, becomes an access to historical search into the host community's social lifestyle and belief systems in very distant past. According to Echeta (2001), "ceramic pots/products whether whole or broken, provide, perhaps, the longest-lasting documentation of a people's way of life in archeology even in subterranean environments" . As if to authenticate his claim, Echeta cites Gardener,(1975) as follows:

Pottery serves as no other artistic medium can, to link the late Mycaenean (sub Mycaenean age) with that of historical Greece. For one thing, it has survived. We can trace a continuity from the sub-Myceanean period into the classical fifth century B.C .entirely in terms of decoration of Greek ceramic ware showing the artist's confrontation with radical new ideas and problems and his equally radical interpretations and solutions.

It is the same subterranean longevity that enabled the archaeological investigations to access clay products in northern Nigerian, globally known as Nok terracotta pieces. These were between 500 BC and 200 AD. The resilience of these pottery products sustained even the delicate features of the images.

Fig 2. One of the Nok Culture Clay Products

\section{Copyright: Treasures of Ancient Nigeria}

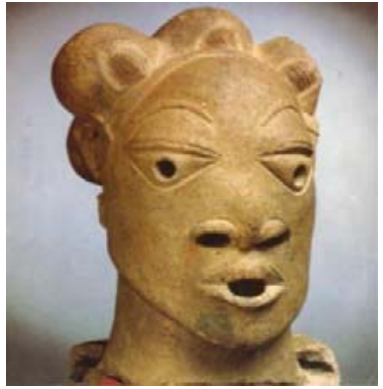

According to Leuzinger (1976) "At a depth of about between fifteen feet seventy feet, hundreds of terracotta fragments have been brought to light, all apparently belonging to the same culture. Thus the Nok culture represents the oldest sculptures demonstrably produced by a Negro people". Leuzinger goes on to say that "geological estimates and carbon 14 dating suggests that Nok works are of great antiquity". Endorsing the intervention of clay (dirt) in historical and cultural documentation through archeology, the same author says that; "On the other hand, as a result of its resistance to climate and insects, terracotta objects are now the most important evidence of prehistoric sculpture. The Nok discoveries, more than two thousand years old are on display at the National museum Lagos, Nigeria.

The Ife terracotta heads of between $12^{\text {th }}$ and $15^{\text {th }}$ centuries fall into the same antiquity mould facilitated by the same fired clay (terracotta) resilience and longevity capacity. These were found in 1953 by Bernard Fagg under the shrine of the goddess of riches known as Olukun. These are on display at the Federal Department Of Antiquity, Lagos, Nigeria.

Fig. 3. One of the Ife Terracotta Heads

Copyright: Treasures of Ancient Nigeria

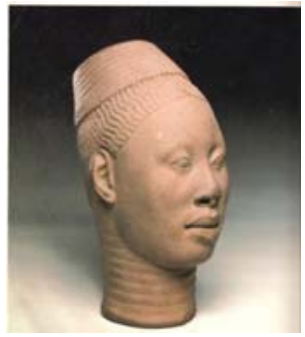


The above sites and citations have remained crucial in the clay product interventions in art and culture. They have documented artistic history and monitored the social genre. These have established themselves as indispensable ingredients in the sustenance of cultural and historical linkage yielding to the overall social structure of a people. Archaeological pottery excavations in Calabar by Prof Ekpo Eyo and much later by Chris Slogar also point to objects of historical documentation many of which are profusely designed. Not only do the pieces show social surface design culture, symbols of far-flung nsibidi cult writings were captured in the wares.

Figs. 3 and 4. Archaeological excavations of terracotta objects.
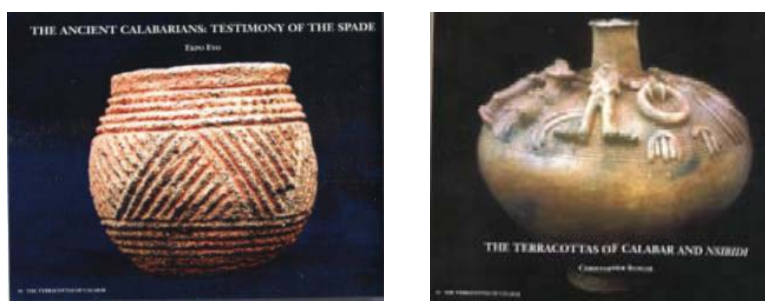

Copyright: Ekpo Eyo and Chris Slogar respectively

About the historical documentation capacity of clay products, Christopher Slogar (2008) has this to say:

\begin{abstract}
For various reasons, the graphic nsibidi usage has declined significantly since the early colonial period, yet this indigenous script remains an important aspect of the cultural fabric of the Cross River region. It is dynamic as the people who invented it and those who continue to develop it today. And while the early history of nsibidi is so far unknown, The Calabar terracottas are shedding new light on the matter and provide valuable evidence that its roots extend more than one thousand years in the past.
\end{abstract}

\title{
6. The Art of Pottery and Tourism
}

Not culture and artistic finds represent objects of his tourist interests. So the Igbo-Ukwu pottery and the Ife excavations fall into the same category. According to Ekpo Eyo (1980):

The government of Nigeria is pleased to lend its art treasures for exhibition in three major American museums These hundred works, from Cultures spanning over two thousand years, belong to Nigeria in particular, but they also belong to mankind at large.

These itinerant exhibitions took place in The Detroit Institute of Arts: January 17 through March 16, 1980, The California Palace of the Legion of Honour, San Francisco: April 28 through June 29, 1980 and at The Metropolitan Museum of Art, New York: August 11 through October 12, 1980. His underscores the depth of value attached to such antiquities.

Over the years, thousands have saved their hard-earned income to be able to afford the cost of viewing these artifacts. The tourists, not only satisfy their appetites by visiting places of interests, they indirectly pay into national economies for the national benefit.

An estimated 657million people crossed their home borders to go on international tourist trips in 1999, generating 450 billion dollars in earning, an increase at 3.2\% over 1998 and the highest revenue ever ever...( Anijah-Obi,2001).

Anijah says "tourism is big business". Nigerian pots have been very much sought-after in the area of tourism and not much can be said outside Dr Ladi Kwali whose life span was between 1925 and 1984.

She was born in the village of Kwali in the Gwari region of Northern Nigeria, where pottery was a common occupation among women. She learned to make pottery as a child using the traditional method of coiling. She made large pots for use as water jars and cooking pots from coils of clay, beaten from the inside with a flat wooden paddle. They were decorated with incised geometric and stylised figurative patterns. Following the traditional African method, they were fired in a bonfire of dry vegetation. (http://www.studiopottery.com/cgi-bin/mp.cgi?item=251 
Her pots were noted for their beauty of form and decoration. Several were acquired by the Emir of Abuja, in whose home they were seen by Michael Cardew in 1950. In 1954, she joined Cardew's pottery training centre in Abuja, its only woman potter, where she learned to throw pots on the wheel. She made dishes, bowls and beakers with sgraffito decoration but also continued to produce pots using her traditional hand building and decorating techniques. Most of these were glazed and fired in a high-temperature kiln and therefore represent an interesting hybrid of traditional African with western studio pottery

Through Kwali's contact with Cardew, she and her work became known in Europe, Britain and America. In the late 1950s and early 1960s, her work was shown to great acclaim in London at the Berkeley Galleries. She became Nigeria's best-known potter, was awarded a doctorate and was made MBE in 1963. The Abuja Pottery was renamed the Ladi Kwali Pottery and a major street in Abuja is called Ladi Kwali Road.

Not only did she excel using "dirt" as her raw material, she also exhibited diligence and professional resilience . Her absolute lack of formal education did not deter her.

Figs 5 and 6. Some of Ladi Kwali's works
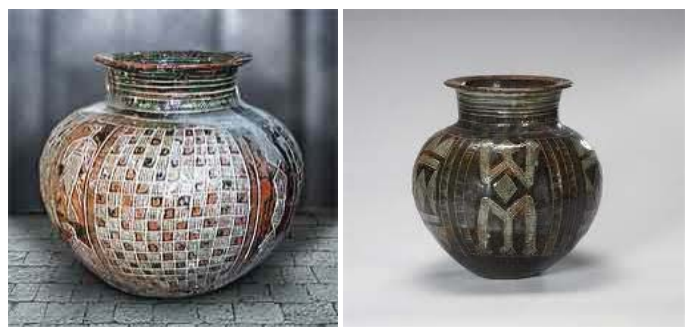

The tourist flavor of her numerous works has clearly been shown. This brough national pride to Nigeria as her country of origin.

In the recording of history, apart from archeological or tourism access to social documentation, other areas of relevance exists. "Dirt"-based ceramic images like "Ogoni Nine" by Tony Umunna is a social protest against the brutal slaughter of Ken Saro Wiwa and his compatriots by hanging authorized by General Sani Abacha as Head of State of Nigeria. The work is a symbol of social injustice. Echeta (2011) says this about Umunna's "Ogoni Nine":

To immortalize this inglorious national experience and to keep the dust in the air, Tony Umunna responded by creating 'Ogoni Nine', a social commentary and a protest imagery...a metaphor for lost lives in crude dispensation of justice. This is a historical documentation from the past to the present and for the future.

Fig. 7. "Ogoni Nine", (1994), 24"x18". Copyright: Umunna

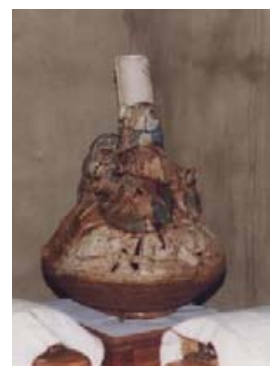

The voiceless images of pottery (clay) suddenly become vocally empowered by the reconfiguration and manipulation of the artist's hand.

\section{Conclusion}

Like the octopus, the tentacles of art have been shown to spread beyond its immediate neighbourhood. Neighborhood 
benefits exist but well and beyond those borders lie multiples of relationships that yield social construction and or reconstruction as well as other areas of gain. The apprenticeship system of traditional pottery is seen to possess the capacity to mould both personal character and corporate relationships. It has become clear that a medium like clay, irrespective of the level of derision applied to it, can generate limitless vista of opportunities for social penetration. Not only does it yield to easy manipulative handling, it hardens under elevated heat levels into rock-like products for both functionality and aestheticism. Dug up twice, clay and its products provide answers to social history and documentation. Once, as a production raw material and twice, as a product of archeological discovery. This second excavation translates into tourism products like the Nok and ife terracotta images, lodged in museums for the consumption of tourists seeking both business and pleasure.

The ideas and prospects of their benefits arising from this paper should prompt all and sundry to action in the areas raised above. Handled properly, the level of joblessness will be trimmed down, wealth will be created through gainful employment, minimize the incidents of social restiveness thereby encourage cultural stability and tourism all round. This is the time to act.

\section{Reference}

Aniakor, C. (2001) Culture and Tourism as Aid to Development in Nigeria (A perspective) in Nigerian Magazine (Special Edition) Abuja. 9-25.

Anijah-Obi, F.N. (2002) Fundamentals of Environmental Education and Management. Calabar: University of Calabar Press.

Echeta, C. (2011) Art in Education: Training the Trainers for National Development. Unpublished article under peer review prior to publication. (Association for Promoting Educational Innovations in Nigeria-APEIN).

................ (2011) Stylistic and Creative Development in Nigerian Art: The Ceramic Art of Tony Ummuna. Unpublished Ph.D Thesis, Department of Fine and Applied Arts, University of Nigeria, Nsukka.

en.wikipedia.org/wiki/Clay From Wikipedia, the free encyclopedia. Retrieved Saturday,29 October 292011.

Eyo, E. (1980) Treasures of Ancient Nigeria. New York: Alfred A. Knopf, Inc.

Eyo, E. and Slogar, C. (2008) The Terracottas of Calabar. Washington: Cultural Preservation Fund.

Gardener, H (1975) Art Through the Ages. 6th ed. New York: Harcourt Brace Jovanovich.

Leuzinger, E (1976) The Art of Black Africa: London: Studio Vista

Okafo, N.B. (2005) Ladi Kwali: The Potter and Her Works. Unpublished Seminar Paper Presented at the University of Nigeria, Nsukka. Department of Fine and Applied Arts.

Okunna, E (2009) Pottery as a Medium of Creative Communication Among Different Cultures in CPAN Journal of Ceramics Nos 2\&3, p.14

http://www.studiopottery.com/cgi-bin/mp.cgi?item=251

http://www.ceramics-aberystwyth.com/ladi-kwali.html

Retrieved from "http://en.wikipedia.org/wiki/Ladi_Kwali" Sunday,18/9/2011.

Wikipedia, the free encyclopedia. Retrieved Sunday,18/9/2011. 
